\title{
Report of a working party on the staffing of endoscopy units
}

In 1985 the British Society of Gastroenterology convened a working party to report on the staffing of endoscopy units in the light of changes which have taken place in the last decade. Its remit was to make recommendations concerning the role, number, and specialised training needs of nurses and other non-medical staff employed in endoscopy (endoscopy assistants). In addition it was to recommend suitable training schemes for endoscopists and consider the implications of individual certification.

The following report was approved by the endoscopy section committee of the British Society of Gastroenterology and was accepted by Council in 1987. Members of the working party were Dr A T R Axon (chairman), Sister P M Bottrill, Dr P Brown, Sister D Campbell, Dr D G ColinJones, Mr M W L Gear, Dr I T Gilmore, Dr D P Jewell, Dr M I Lavelle, and Dr A I Morris.

\section{Background}

Gastrointestinal endoscopy is now routinely available within district general hospitals in the United Kingdom and in recent years has experienced a huge growth in demand for its services. This success has been contributed to not only by improved diagnostic accuracy over other investigative techniques, but especially by increasing use of endoscopy for therapeutic procedures. A previous report by the endoscopy section committee of the British Society of Gastroenterology on the design of gastrointestinal endoscopy units ${ }^{2}$ indicated that there was a $14 \%$ annual rate of increase in the number of upper gastrointestinal endoscopies carried out each year. More impressive than this was the number of therapeutic upper gastrointestinal procedures which had increased by $34 \%$ per annum. This same rate of increase was experienced in colonoscopy $(70 \%$ annual rate of increase in operative colonoscopy) and ERCP (28\% annual rate of increase). Whilst it is not anticipated that the demand will increase at this rate in the years ahead, newer techniques such as biliary stenting for malignant jaundice and cancer prevention by colonoscopy will also substantially increase the demand for endoscopy. The development of endoscopy should now be planned logically to cater for further expansion and must include the provision of trained staff to run a safe and efficient service.

The data quoted in the following report have been obtained from the results of a questionnaire which was circulated to randomly selected Health Districts in England and Wales during $1986 .{ }^{3}$ The report is in two sections, the first dealing with nursing and ancillary staff, the second is concerned with endoscopy training for medical staff.

\section{Section 1 - Nursing and ancillary staff}

STAFFING I.EVEIS

The state of non-medical staffing in endoscopy units reflects incoordinated growth and the struggle for adequate funds and staff. Some are well staffed with fully trained endoscopy assistants working on a full time basis with good administrative and clerical backup whereas other smaller units survive on a part-time basis with relatively untrained staff.

Staffing levels should relate to the workload of the endoscopy unit, which is affected by the population served and by local methods of practice such as the provision of open access. The number of non-medical staff required for endoscopy must take account of staffing in the endoscopy room, preparation and recovery areas, and in administration. A flexible approach is necessary as lists may run concurrently where two endoscopy rooms are available and provision must be made for holiday and sick leave. In general, staff will be required to cover the unit from $800 \mathrm{am}$ to $500 \mathrm{pm}$ in order to allow morning $(830-1230)$ and afternoon (130-430) sessions. It is not current practice to budget for on-call duties, but there is an increasing demand for emergency endoscopy (in our survey $83 \%$ of units provided out of hours cover). Trained staff are needed to clean and disinfect equipment and to help with newer haemostatic equipment often used out of hours.

Staffing levels recommended here are those required for an average sized district general hospital serving a population of about 250000 .

RECOMMENDATIONS

(1) The nurse in charge

(i) The nurse in charge of the endoscopy unit should be of sister grade and be responsible for the day to day organisation and running of the unit including the training of endoscopy assistants, care of the equipment, and the maintenance of high standards of patient care. This appointment must be made in consultation with the clinician in charge of the unit who should have overall control of the endoscopy service (as opposed to the day to day running of it). (ii) The appointee should be professionally accountable 
to a clinical nurse manager. (iii) The duties of the nurse in charge include responsibility for personnel matters, health and safety, and communication and liaison with the rest of the hospital.

\section{(2) Endoscopy assistants}

(i) Two endoscopy assistants, at least one of whom must be a qualified nurse (SEN or SRN), are required at each endoscopy table. (ii) A qualified nurse should be responsible for patient preparation ensuring that the patient is given a full explanation of the procedure. (iii) A qualified nurse should be responsible for supervising the patients' recovery. (iv) Radiographers, theatre technicians, and laboratory technicians, following a course of training, may work as endoscopy assistants under nursing direction, but should not be responsible for patient preparation or patient recovery. They should also be accompanied by at least one qualified nurse when assisting at the endoscopy table. (v) A qualified nurse, fully trained as an endoscopy assistant, should be available on call in hospitals where an out of hours emergency endoscopy service is provided.

\section{(3) Administrative staff}

(i) Appropriate secretarial and clerical staff are necessary for endoscopy and should be provided over and above the secretariat employed for the non-endoscopy part of the consultant's workload and should be of a calibre capable of responding to the demands of the service. (ii) Voluntary workers shoud be encouraged as they may provide great assistance in busy units, releasing clinical staff for more urgent clinical duties.

TRAINING REQUIREMENTS FOR ENDOSCOPY

ASSISTANTS

In-service experience is a crucial part of training, but nurses wishing to claim an expertise in endoscopy should undergo specialised training. Courses offered by commercial companies are of great value and should be encouraged, but should not constitute the sole basic training offered to endoscopy assistants. All nurses working in this specialised area require a basic training with provision for an annual update. The nurse in charge of an endoscopy unit will require further training to undertake this role.

RECOMMENDATIONS

(1) The training schemes agreed by the endoscopy section committee should be regularly reviewed and amended as necessary. All training courses offered should be approved by the endoscopy section of the British Society of Gastroenterology.

(2) The training scheme for endoscopy assistants should be as follows: (i) They should attend a two day basic training course within one year of appointment. (ii) Shortly after appointment two weeks should be spent gaining practical experience under supervision. This should be done in an established busy endoscopy unit carrying out at least 1000 procedures per annum ideally within easy access of the assistant's hospital. (iii) They should attend annual update sessions in the form of study days or advanced training courses. (iv) They should be encouraged to become members of the assistants group of the endoscopy section of the
British Society of Gastroenterology and receive the information circulated by that organisation.

(3) Training for nurses in charge of endoscopy units: (i) They should undergo a longer training course such as the ENB course 906 before or very soon after appointment. (ii) They should be members of the endoscopy section of the BSG.

(4) To correct the shortage of courses the following action should be taken by the British Society of Gastroenterology: (i) They should consider providing their own two day courses. (ii) They should approach centres to encourage them to set up further ENB courses.

(5) The attention of health authorities should be drawn to the financial implications of endoscopy assistant training.

CERTIFICATION OF ENDOSCOPY ASSISTANTS

There is a need for a dedicated group of assistants with a continuing interest in the technique and they should be encouraged to attend courses and undertake practical training, official certification is, however, unnecessary.

\section{Section 2 - Medical staff}

ENDOSCOPY TRAINING FOR MEDICAL STAFF

Medical staff from a wide range of specialties and grades provide endoscopy services, but most are under the general direction of a physician. There is a steady growth in the number and range of endoscopic procedures carried out. This trend is likely to continue as $79 \%$ of doctors in charge of endoscopy units recognise a need to expand their service, a high proportion require more endoscopists and $60 \%$ consider that a formal training scheme is desirable."

Basic endoscopy and colonoscopy can be taught at most district general hospitals where there is a sufficiently large workload and variety of procedures. Endoscopic retrograde cholangiopancreatography should be taught in specialised centres, which have an adequate throughput.

As there is fierce competition for consultant posts there is considerable pressure on trainees to be 'fully trained' in all aspects of gastroenterology including endoscopy. It is arguable, however, whether all gastroenterologists need to acquire the skills of ERCP. In larger centres one gastroenterologist may specialise in colonoscopy and another in ERCP, while ERCP cannot be justified in every smaller district general hospital.

General practitioner clinical assistants, hospital practitioners and hospital staff should be accepted as trainees. The steadily increasing demand for diagnostic endoscopy requires permanent endoscopists in addition to consultant staff. The general practitioner endoscopist provides this continuity for diagnostic endoscopy. Most therapeutic procedures will be carried out by hospital staff because of the risk of complications requiring continuing care.

GENERAL RECOMMENDATIONS

(1) Any practitioner who is to have a sessional commitment to endoscopy should receive formal training.

(2) Wherever endoscopy is taught it should be provided as part of an overall gastroenterology service with cooperation 
between physician, surgeon, radiologist, and pathologist. Joint ward rounds, clinics and clinical meetings are desirable to achieve high standards of patient care.

(3) In-service experience should be supplemented by attendance at courses approved or organised by the endoscopy section committee. The purpose of this is to update endoscopists about newer equipment, techniques, and management.

\section{RECOMMENDATIONS FOR TRAINING IN OGD}

(1) Facilities

(i) Training should be in a unit carrying out a minimum of 1000 OGD examinations per year so that a full range of conditions is observed and diagnostic and therapeutic measures encountered. (ii) The training unit should be furnished with modern endoscopy equipment. Fluoroscopy, not necessarily in the endoscopy unit, shoud be available for selected cases such as endoscopic intubation. At least one teaching attachment (training arm) or video system is essential.

\section{(2) Endoscpic experience}

(i) Trainee endoscopists should attend regular weekly sessions (or more often) for at least six months. (ii) At least 150-200 examinations should be completed with some degree of supervision. (iii) Therapeutic endoscopy is considerably more hazardous and should be taught only after the basic training for OGD has been completed. It should include attendance at sessions for appropriate techniques for a further period of 6-12 months. Procedures should be carried out initially under supervision and subsequently independently. (iv) A written record of the number and variety of procedures carried out under supervision and independently should be kept for inspection.

\section{(3) Courses in diagnostic and therapeutic $O G D$}

(i) These courses should be approved by the endoscopy section committee of the British Society of Gastroenterology and be provided on a regional or national basis. (ii) Trainee endoscopists should attend courses on basic endoscopy and therapeutic endoscopy. These should include such topics as patient care, maintenance, cleaning and disinfection of endoscopes and equipment, electrical hazards, recognition and management of the complications of endoscopy, and sessions on therapeutic endoscopy such as oesophageal stricture dilatation, prosthetic tube placement, polypectomy, variceal injection, and electrocoagulation. The general administration of an endoscopy unit should also be covered.

RECOMMENDATIONS FOR TRAINING IN COLONOSCOPY AND POLYPECTOMY

As with $\mathrm{OGD}$ in-service training is most important.

(1) Training units shoud undertake at least 200 procedures per year and to allow time for training there should be at least two colonoscopy lists per week.

(2) The role of histology, combined x-ray and surgical meetings with review of operative findings are stressed.

(3) Modern colonoscopic equipment is essential and fluoroscopy should be available.
(4) Apart from the acquisition of technical expertise the trainee should understand the mechanics of the procedure as well as the indications for colonoscopy, its limitations and the complications which may occur. Techniques of patient preparation should be understood. Trainees should attend a course on colonoscopy covering these topics.

(5) Although the performance of a specific number of techniques does not imply competence, each trainee should observe and assist at 50 colonoscopic examinations and subsequently complete 50 successful colonoscopies on his/ her own under supervision. The trainee should have acquired experience in polypectomy.

(6) Courses in colonoscopy should be approved by or be carried out under the aegis of the endoscopy section committee.

\section{TRAINING IN FIBRESIGMOIDOSCOPY}

The shorter and cheaper flexible fibresigmoidoscope is used to obtain views of the rectum and distal colon. It is easier and quicker to use than a colonoscope and it is of value in outpatients or endoscopy units. The procedure should be taught under supervision until confidence is acquired. Experience in its use, however, does not imply expertise with a colonoscope.

\section{RECOMMENDATIONS FOR TRAINING IN ERCP AND}

THERAPEUTIC ERCP

The therapeutic aspects of endoscopic sphincterotomy for gall stone retrieval and palliative biliary stenting ensure that the main thrust of ERCP is towards the biliary tract. Training in the technique should emphasise these aspects although retrograde pancreatography is still carried out for detailed assessment of pancreative anatomy. Endoscopic retrograde cholangiopancreatography is expensive in equipment and staffing so there is a case for limiting the procedure to certain subregional centres. The questionnaire ${ }^{3}$ highlights the large number of centres performing ERCP, at the same time showing that most ERCP lists are small (1-2 patients).

(1) Trainees should have a sound experience of upper GI endoscopy before starting ERCP.

(2) As the technique is radiological as well as endoscopic it is essential to have the support of a consultant radiologist with an interest in ERCP.

(3) Training centres should have a patient throughput which is adequate to teach ERCP in the general context of managing complex pancreaticobiliary problems undertaking at least 200 procedures per annum. There should be close liaison with surgeons working in this field and with radiologists skilled in alternative imaging and interventional techniques. Joint meetings of different disciplines should be held to discuss cases.

(4) Attendance at courses in diagnostic and therapeutic ERCP are essential not only for trainees but for keeping trainers abreast of developments.

(5) Endoscopists cannot be considered competent until 
they are able to cannulate over $90 \%$ of pancreatic ducts, and $80 \%$ of bile ducts. The experience needed to achieve this success rate will vary, but in general an endoscopist should carry out at least 100 procedures under supervision and be achieving a high percentage of success before performing the procedure independently.

(6) $\mathrm{He} / \mathrm{she}$ should be able to interpret the radiological findings, and assess the significance of these in the context of the patient's illness.

(7) $\mathrm{He} / \mathrm{she}$ should have experience in endoscopic sphincterotomy and have assisted in the insertion of endoscopic biliary stents.

(8) Courses should be approved by or be carried out under the aegis of the endoscopy section committee of the BSG.

CERTIFICATION FOR ENDOSCOPISTS

Individual certification for endoscopists is undesirable as it would impinge on the responsibilities of the Committee for Higher Specialist Training. Prospective endoscopists should keep a record book designed by the endoscopy section committee of the BSG ${ }^{+}$It should be available for inspection and will contain details of training including attendance at courses and the number and variety of procedures carried out.

\section{Bibliography}

1 The full report of the working party including a section on the financial implications of the recommendations is available as a pamphlet from the BSG Secretariat. BSG Headquarters, 3 St Andrew's Place, Regent's Park, London. NW1.

2 BSG Report - Design of gastrointestinal endoscopy units 1983. Available from BSG Secretariat, BSG Headquarters, 3 St Andrew`s Place, Regent's Park. London. NW1.

3 Results of a questionnaire concerning the staffing and administration of endoscopy in England and Wales. Gut 1987 (in press).

4 Booklet in preparation and available from BSG Secretariat, BSG Headquarters, 3 St Andrew's Place, Regent's Park, London, NWI. 